\title{
Comparison of Immediate Results and Follow-up of Patients with Single-Vessel and Multivessel Coronary Artery Disease Younger than 50 Years of Age Undergoing Coronary Stent Implantation
}

\author{
Alexandre L. Anello, Isaac Moscoso, Ricardo J. Tófano, Adnan A. Salman, Salvador A. B. Cristóvão, \\ Maria Fernanda Z. Mauro, João Batista de O. Neto, José A. Mangione
}

São Paulo, SP - Brazil

\begin{abstract}
Objective - To assess the in-hospital results and clinical follow-up of young patients (<50 years) with multivessel coronary artery disease undergoing stent implantation in native coronary arteries and to compare their results with those of patients with single-vessel coronary artery disease.
\end{abstract}

Methods - We retrospectively studied 462 patients undergoing coronary stent implantation. Patients were divided into 2 groups: group I (G-I) - 388(84\%) patients with single-vessel coronary artery disease; and group II (G-II) $74(16 \%)$ patients with multivessel coronary artery disease.

Results - The mean age of the patients was $45 \pm 4.9$ years, and the clinical findings at presentation and demographic data were similar in both groups. The rate of clinical success was $95 \%$ in $G-I$ and $95.8 \%$ in $G-I I(P=0.96)$, with no difference in regard to in-hospital evolution between the groups. Death, acute myocardial infarction, and the need for myocardial revascularization during clinical follow-up occurred in $10.1 \%$ and $11.2 \%(P=0.92)$ in $G-I$ and $G-I I$, respectively. By the end of 24 months, the actuarial analysis showed an event-free survival of $84.6 \%$ in $G$ I and $81.1 \%$ in $G-I I(P=0.57)$.

Conclusion - Percutaneous treatment with coronary stent implantation in young patients with multivessel disease may be safe with a high rate of clinical success, a low incidence of in-hospital complications, and a favorable evolution in clinical follow-up.

Keywords: multivessel, stent percutaneous, coronary angioplasty

Hospital Beneficência Portuguesa de São Paulo

Mailing address: José Armando Mangione - Hospital Beneficência Portuguesa de São Paulo - Rua Maestro Cardim, 769 - S/71 - Cep 01323-900 - São Paulo, SP, Brazil - E-mail: uci@oul.com.br

Received 11/18/02

Accepted 5/26/03

English version by Stela Maris C. e Gandour
The prevalence of coronary artery disease, especially in its multivessel form, in the population aged less than 50 years has increased. This fact may be partially explained by the current lifestyle favoring sedentary habits, stress, obesity, smoking, and the greater incidence of type II diabetes mellitus, well-known factors of coronary risk ${ }^{1-3}$.

Before the appearance of stents, the use of coronary angioplasty in the treatment of patients with multivessel disease was limited by the impossibility of approaching more complex lesions and the elevated rate of restenosis ${ }^{4-6}$. With the increased use of devices in the treatment of coronary artery disease, several studies have assessed their use in select or unselect groups of patients with multivessel disea$\mathrm{se}^{7,8}$; however, the reports on the benefits of these devices in younger patients are scarce.

The objective of this study was to assess the in-hospital results and the clinical follow-up of patients with multivessel disease aged less than 50 years undergoing coronary stent implantation in native coronary arteries and to compare them with those of patients with single-vessel disease.

\section{Methods}

This study comprised a consecutive series of 462 patients aged less than 50 years, undergoing percutaneous coronary intervention with coronary stent implantation from July 1997 to June 2002 at the Hospital da Beneficiência Portuguesa of São Paulo.

The study sample comprised patients with "de novo" lesions in the native coronary artery with clinical findings of stable or unstable angina or documented myocardial ischemia. Patients undergoing angioplasty in the acute phase of myocardial infarction, adjunct procedures of atheroablation, and those with contraindications for antithrombotic or platelet antiaggregating therapy were excluded.

The patients were divided into the following 2 groups 
according to the number of vessels treated: group I (G-I) $388(84 \%)$ patients with single-vessel coronary artery disease; and group II (G-II) - 74 (16\%) patients with multivessel coronary artery disease.

All patients underwent 12-lead electrocardiography, before and after the procedure, for detecting ischemic changes or the appearance of new $Q$ waves, or both. Blood samples were collected before the procedure and every 8 hours after the procedure for measuring the CKMB isoenzyme. Acute myocardial infarction was defined as an increase in CKMB isoenzyme greater than 3 times its normal value or the appearance of new $\mathrm{Q}$ waves in 2 or more contiguous leads in the electrocardiogram, or both ${ }^{9}$.

Contrast-induced nephropathy was characterized by an elevation in creatinine greater than $50 \%$ of the value on admission or the need for dialysis.

Effort angina was classified according to the criterion of the Canadian Society of Cardiology ${ }^{10}$, and unstable angina was classified according to the TIMI risk score ${ }^{11}$.

The vascular complications were classified as follows: a) major - bleeding with a reduction $>5 \mathrm{~g} / \mathrm{dL}$ in the hemoglobin levels (puncture site, gastrointestinal, or genitourinary systems), hemorrhagic cerebral stroke, or the need for surgical repair of the artery used as an access route; $b$ ) minor - bleeding with a reduction $>3 \mathrm{~g} / \mathrm{dL}$ and $<5 \mathrm{~g} / \mathrm{dL}$ in the hemoglobin levels.

Clinical follow-up was performed through medical visits or telephone contact.

Significant coronary artery lesion was defined as a stenosis $\geq 70 \%$ assessed on quantitative digital angiography. The patients with multivessel disease selected had this degree of obstruction in at least 2 major epicardial vessels or in branches with a diameter $>2.5 \mathrm{~mm}$.

The complexity of the lesions was classified into types A, B1, B2, or C, according to the criteria of the American Heart Association and American College of Cardiology ${ }^{12}$ modified by Ellis et al ${ }^{13}$.

Angiographic success was defined as a residual lesion $<20 \%$ with TIMI III flow, and clinical success ${ }^{14}$ was defined as angiographic success in the absence of death, acute myocardial infarction, and need for emergency myocardial revascularization in the in-hospital phase.

The patients were medicated with oral acetylsalicylic acid $(200 \mathrm{mg} /$ day for an indefinite time) and ticlopidine (500 $\mathrm{mg}$ /day) or clopidogrel (attack dose of $300 \mathrm{mg}$ followed by 75 $\mathrm{mg}$ /day) initiated, whenever possible, 3 days before the intervention and maintained for 30 days.

The femoral access route was preferred for the intervention. At the beginning of the procedure, intravenous heparin was administered at a dosage of $100 \mathrm{UI} / \mathrm{kg}$ of weight. After passing a 0.014 extrasupport guidewire, predilation with a balloon catheter was performed or a stent was directly implanted in selected cases.

All stents implanted during the study period were included in this analysis, and their implantation aimed at reaching a balloon/artery diameter ratio of 1.1-1.2. The mean final pressure of inflation was 15 atmospheres.
When the procedure was over, the arterial introducers were removed when the activated clotting time was $<180$ seconds.

The use of glycoprotein (GP) IIb/IIIa inhibitors was up to the surgeon.

The primary outcome of the study was to assess the association of major cardiac events as follows: death from a cardiovascular cause, nonfatal acute myocardial infarction, and need for a new revascularization during clinical follow-up.

The following were considered secondary outcomes: clinical success index, in-hospital evolution, and recurrence of angina during clinical follow-up.

The continuous variables were expressed as mean and standard deviation and were compared using the Student $t$ test. The categorical variables were presented as percentages, and the groups were compared using the chi-square test or Fisher exact test. The statistical significance level of $\mathrm{P} \leq 0.05$ was adopted.

Event-free survival was analyzed using the KaplanMeier curve.

\section{Results}

The mean age of the patients studied was $45 \pm 4.9$ years. The mean ages of G-I and G-II patients were, respectively, $45 \pm 5$ years and $46 \pm 7.9$ years $(\mathrm{P}=0.11)$. In regard to sex, females represented $23.5 \%$ and $18.9 \%$ of G-I and G-II patients, respectively $(\mathrm{P}=0.59)$.

The clinical findings at the patient's presentation and the incidence of diabetes mellitus, systemic arterial hypertension, smoking, previous acute myocardial infarction, previous surgical or percutaneous revascularization, and ejection fraction $<30 \%$ were similar between the groups (tab.I).

The mean number of lesions treated in G-I and G-II was, respectively, $1.09 \pm 0.42$ and $2.42 \pm 0.35(\mathrm{P}<0.001)$, and the stent/patient ratio in G-I and G-II was, respectively, $1.03 \pm 0.55$ and $1.47 \pm 0.54(\mathrm{P}<0.001)$. Stents were implanted in $62 \%$ of the lesions treated in the patients with multivessel coronary artery disease (G-II).

In G-II, $95.9 \%$ of the patients had lesions in 2 coronary arteries and $4.1 \%$ had lesions in 3 arteries.

No difference was observed in regard to the type of lesions treated in G-I and G-II, respectively: $\mathrm{A}+\mathrm{B}_{1} 33.4 \%$ vs $27.4 \%(\mathrm{P}=0.33), \mathrm{B}_{2} 39.1 \%$ vs $40.8 \%(\mathrm{P}=0.86)$, and $\mathrm{C} 27.5 \%$ vs $31.8 \%(\mathrm{P}=0.48)$. Comparing the coronary arteries approached, the major artery treated in G-I was the anterior descending artery (50\% vs $31.4 \%$ in G-II) (P=0.009), while in G-II, the major artery treated was the circumflex artery $(34.6 \%$ vs $18 \%$ in G-I $)(\mathrm{P}<0.001)$. The right coronary artery and the left main coronary artery were treated in the same proportion in both groups.

The inhibitors of GP IIb/IIIa were used in $8 \%$ and $9.5 \%$ of the procedures in GI and GII, respectively ( $\mathrm{P}=0.87)$ (tab. II).

Clinical follow-up data were obtained in 443 patients, $372(98.9 \%)$ in G-I and 71 (97.3\%) in G-II ( $\mathrm{P}=0.93)$, with a mean follow-up of $206 \pm 204$ days for G-I and 196 \pm 160 days for $\mathrm{G}-\mathrm{II}(\mathrm{P}=0.69)$. 


\begin{tabular}{|c|c|c|c|c|}
\hline \multicolumn{5}{|c|}{ Table I - Clinical characteristics } \\
\hline & Total & Group I & Group II & $p$ \\
\hline Total & $462(100 \%)$ & $388(84 \%)$ & $74(16 \%)$ & - \\
\hline Age (years) ${ }^{\dagger}$ & $45 \pm 4.95$ & $45 \pm 4.96$ & $46 \pm 4.79$ & 0.11 \\
\hline Female sex & $105(22.7 \%)$ & $91(23.5 \%)$ & $14(18.9 \%)$ & 0.59 \\
\hline \multicolumn{5}{|l|}{ Clinical findings } \\
\hline Asymptomatic & $98(21.2 \%)$ & $83(21.4 \%)$ & $15(20.3 \%)$ & 0.98 \\
\hline Stable angina & $200(43.3 \%)$ & $166(42.8 \%)$ & $34(45.9 \%)$ & 0.84 \\
\hline Unstable angina & $164(35.5 \%)$ & $139(35.8 \%)$ & $25(33.8 \%)$ & 0.91 \\
\hline Diabetes mellitus & $85(18.4 \%)$ & $71(18.3 \%)$ & $14(18.9 \%)$ & 0.95 \\
\hline Smoking & $209(45.2 \%)$ & $174(44.8 \%)$ & $35(47.3 \%)$ & 0.90 \\
\hline Dyslipidemia & $198(42.9 \%)$ & $168(43.3 \%)$ & $30(40.5 \%)$ & 0.87 \\
\hline Arterial hypertension & $282(61 \%)$ & $236(60.8 \%)$ & $46(62.2 \%)$ & 1.00 \\
\hline LVEF $<30 \%$ & $15(3.2 \%)$ & $13(3.4 \%)$ & $2(2.7 \%)$ & 0.94 \\
\hline Previous AMI & $207(44.8 \%)$ & $179(46.1 \%)$ & $28(37.8 \%)$ & 0.48 \\
\hline Previous MR & $21(4.5 \%)$ & $15(3.9 \%)$ & $6(8.1 \%)$ & 0.22 \\
\hline Previous PCI & $32(6.9 \%)$ & $27(7 \%)$ & $5(6.8 \%)$ & 0.85 \\
\hline
\end{tabular}

\begin{tabular}{|c|c|c|c|c|}
\hline \multicolumn{5}{|c|}{ Table II - Angiographic characteristics } \\
\hline & Total & Group I & Group II & $p$ \\
\hline Total of patients & $462(100 \%)$ & $388(84 \%)$ & $74(16 \%)$ & - \\
\hline Lesions treated & $601(100 \%)$ & $422(70.2 \%)$ & $179(29.8 \%)$ & - \\
\hline Implanted stents & $510(100 \%)$ & $400(78.4 \%)$ & $110(21.6 \%)$ & - \\
\hline Lesions/patient $^{\dagger}$ & $1.30 \pm 0.37$ & $1.09 \pm 0.42$ & $2.42 \pm 0.35$ & $<0.001$ \\
\hline Stents/patient ${ }^{\dagger}$ & $1.10 \pm 0.55$ & $1.03 \pm 0.55$ & $1.47 \pm 0.54$ & $<0.001$ \\
\hline Double-vessel & $71(15.4 \%)$ & - & $71(95.9 \%)$ & - \\
\hline Triple-vessel & $3(0.6 \%)$ & - & $3(4.1 \%)$ & - \\
\hline \multicolumn{5}{|l|}{ Types of lesions } \\
\hline $\mathrm{A}+\mathrm{B}_{1}$ & $190(31.6 \%)$ & $141(33.4 \%)$ & $49(27.4 \%)$ & 0.33 \\
\hline $\mathrm{B}_{2}$ & $238(39.6 \%)$ & $165(39.1 \%)$ & $73(40.8 \%)$ & 0.86 \\
\hline $\mathrm{C}$ & $173(28.8 \%)$ & $116(27.5 \%)$ & $57(31.8 \%)$ & 0.48 \\
\hline Right coronary & $194(32 \%)$ & $134(31.6 \%)$ & $60(33.5 \%)$ & 0.83 \\
\hline $\mathrm{LCA}^{\#}$ & $3(0.5 \%)$ & $2(0.4 \%)$ & $1(0.5 \%)$ & 0.62 \\
\hline Anterior descending artery & $267(44.5 \%)$ & $211(50 \%)$ & $56(31.4 \%)$ & 0.009 \\
\hline Circumflex artery & $37(23 \%)$ & $75(18 \%)$ & $62(34.6 \%)$ & $<0.001$ \\
\hline Use of inhibitor of GP IIb/IIIa & $38(8.2 \%)$ & $31(8 \%)$ & $7(9.5 \%)$ & 0.87 \\
\hline
\end{tabular}

Primary outcome, such as death from a cardiovascular cause, acute myocardial infarction, and need for new revascularization, occurred in $10.1 \%$ and $11.2 \%$ of the G-I and G-II patients, respectively $(\mathrm{P}=0.92)$.

The incidence of death during that period in G-II was $0 \%$ and in $\mathrm{G}-\mathrm{II} 0.8 \%(\mathrm{P}=0.97)$. The rates of acute myocardial infarction and need for new revascularization were $0.8 \%$ and $1.4 \%(\mathrm{P}=0.84)$, respectively, in $\mathrm{G}-\mathrm{I}$, and $8.5 \%$ and $9.8 \%$ $(\mathrm{P}=0.88)$, respectively, in G-II (tab. IV).

The actuarial analysis by the end of 24 months showed an event-free survival of $84.6 \%$ and $81.1 \%(\mathrm{P}=0.57)$ in G-I and G-II, respectively (fig. 1).

Clinical success was high and similar in G-I and G-II: $95 \%$ and $95.8 \%(\mathrm{P}=0.96)$, respectively.

The in-hospital evolution showed rates of major adverse cardiac events of $1.9 \%$ and $2.8 \%$ in G-I and G-II, respectively $(\mathrm{P}=0.96)$. No deaths occurred during the in-hospital phase. The incidences of stroke were $1.8 \%$ and $1.4 \%$ in G-I and G-II, respectively $(\mathrm{P}=0.82)$, and the incidences of renal failure after the intervention were $0.8 \%$ and $2.7 \%$ in G-I and G-II, respectively ( $\mathrm{P}=0.4)$ (tab. III).

Recurrence of angina pectoris during clinical followup was observed in $12.6 \%$ of the patients in G-I and in $7 \%$ of the patients in $\mathrm{G}-\mathrm{II}(\mathrm{P}=0.31)$.

\section{Discussion}

When choosing the invasive strategy for the treatment of multivessel coronary artery disease, it is important to consider the degree of revascularization that may be obtained, because this, when total revascularization is achieved, enables better angina control and longer survival during clinical follow-up ${ }^{15}$.

The technique of percutaneous treatment using coronary angioplasty with a balloon catheter has limitations, mainly due to the impossibility of approaching more com- 


\begin{tabular}{|c|c|c|c|c|}
\hline \multicolumn{5}{|c|}{ Table III - Results of in-hospital phase } \\
\hline & Total & Group I & Group II & $p$ \\
\hline Successful procedure & $449(97.2 \%)$ & $376(96.9 \%)$ & $73(98.6 \%)$ & 0.99 \\
\hline Clinical success & $440(95.4 \%)$ & $369(95 \%)$ & $71(95.8 \%)$ & 0.97 \\
\hline Failure & $13(2.8)$ & $12(3.1)$ & $1(1.4)$ & 0.67 \\
\hline MACE & $9(1.8 \%)$ & $7(1.9 \%)$ & $2(2.8 \%)$ & 0.96 \\
\hline Death & - & - & - & - \\
\hline AMI & $5(1 \%)$ & $4(1.1 \%)$ & $1(1.4 \%)$ & 0.71 \\
\hline Emergency MR & $4(0.8 \%)$ & $3(0.8 \%)$ & $1(1.4 \%)$ & 0.84 \\
\hline Surgical & $2(0.4 \%)$ & $2(0.5 \%)$ & $0(0 \%)$ & 0.73 \\
\hline Percutaneous & $2(0.4 \%)$ & $1(0.3 \%)$ & $1(1.4 \%)$ & 0.73 \\
\hline Vascular complications & $9(1.9 \%)$ & $8(2.1 \%)$ & $1(1.4 \%)$ & 0.95 \\
\hline Minor & $6(1.3 \%)$ & $5(1.3 \%)$ & $1(1.4 \%)$ & 0.60 \\
\hline Major & $3(0.6 \%)$ & $3(0.8 \%)$ & $0(0 \%)$ & 0.97 \\
\hline $\mathrm{ARF}$ & $5(1.1 \%)$ & $3(0.8 \%)$ & $2(2.7 \%)$ & 0.40 \\
\hline Stroke & $8(1.7 \%)$ & $7(1.8 \%)$ & $1(1.4 \%)$ & 0.83 \\
\hline
\end{tabular}

\begin{tabular}{|c|c|c|c|c|}
\hline \multicolumn{5}{|c|}{ Table IV - Results of clinical outcome } \\
\hline & Total & Group I & Group II & $p$ \\
\hline Total of patients followed up & $443(98.7 \%)$ & $372(98.9 \%)$ & $71(97.3 \%)$ & 0.93 \\
\hline Mean time (days) & $204 \pm 197.4$ & $206 \pm 204.2$ & $196 \pm 160.2$ & 0.70 \\
\hline \multicolumn{5}{|l|}{ Clinical findings } \\
\hline Asymptomatic & $383(86.5 \%)$ & $316(84.9 \%)$ & $66(93 \%)$ & 0.64 \\
\hline Recurring angina & $50(11.3 \%)$ & $47(12.6 \%)$ & $5(7 \%)$ & 0.31 \\
\hline Stable angina & $32(7.2 \%)$ & $29(7.8 \%)$ & $4(5.6 \%)$ & 0.73 \\
\hline Unstable angina & $18(4.1 \%)$ & $18(4.8 \%)$ & $1(1.4 \%)$ & 0.34 \\
\hline MACE & $45(9.9 \%)$ & $37(10.1 \%)$ & $8(11.2 \%)$ & 0.93 \\
\hline Death & $3(0.7 \%)$ & $3(0.8 \%)$ & $0(0 \%)$ & 0.97 \\
\hline AMI & $4(0.6 \%)$ & $3(0.8 \%)$ & $1(1.4 \%)$ & 0.84 \\
\hline Revascularization & $38(8.6 \%)$ & $31(8.5 \%)$ & $7(9.8 \%)$ & 0.88 \\
\hline \multicolumn{5}{|l|}{ Death } \\
\hline Cardiac & $2(0.5 \%)$ & $2(0.6 \%)$ & $0(0 \%)$ & 0.73 \\
\hline Noncardiac & $1(0.2 \%)$ & $1(0.3 \%)$ & $0(0 \%)$ & 0.35 \\
\hline \multicolumn{5}{|l|}{ Revascularization } \\
\hline Percutaneous & $34(7.7 \%)$ & $27(7.3 \%)$ & $7(9.8 \%)$ & 0.65 \\
\hline Surgical & $4(0.9 \%)$ & $4(1.2 \%)$ & $0(0 \%)$ & 0.85 \\
\hline
\end{tabular}

plex lesions and to the high rate of coronary restenosis. With the appearance of coronary stents, the indications for percutaneous treatment increased, and a simultaneous significant reduction in the rates of restenosis and in the immediate complications of the procedure occurred, providing a better clinical evolution according to the STRESS and BENESTENT randomized studies ${ }^{16-18}$. After these studies, the comparison of the percutaneous treatment with stents and the surgical treatment in patients with multivessel coronary artery disease became necessary.

The ARTS trial ${ }^{7}$ compared the use of stents and surgery in patients with multivessel coronary artery disease and showed a significant evolution in the group undergoing percutaneous treatment. The capacity of revascularization of the 2 methods was the same: 2.7 lesions treated with stents and 2.7 anastomoses. In addition, a similar clinical evolution, assessed by the occurrence of death, nonfatal acute myocardial infarction, and stroke, was observed. The need for new revascularization, although smaller, as compa- red with the studies using only the balloon catheter, was greater in the percutaneous group ( $21 \%$ vs $3.8 \%$ ) by the end of 1 year $(\mathrm{P}<0.01)$.

The SoS trial ${ }^{19}$, which also compared the use of stents and surgery in patients with multivessel coronary artery disease, with 2.7 lesions treated with stents and 2.8 with anastomoses, showed a similar incidence of death or nonfatal Q infarction in the groups in a 2-year follow-up. The overall mortality was $5 \%$ in the group treated with stent and $2 \%$ in the group treated with surgery $(\mathrm{P}=0.01)$; however, $60 \%$ of the deaths in the intervention group were of noncardiac cause. Need for new revascularization was greater in the percutaneous revascularization group (21\%) than in the surgery group $(6 \%)(\mathrm{P}<0.001)$.

The ERACI-II ${ }^{20}$, a randomized multicenter study comparing percutaneous revascularization using stents and surgical revascularization in patients with multivessel coronary artery disease, reported a lower rate of cardiac events in the percutaneous group in 30 days. In the follow-up of 


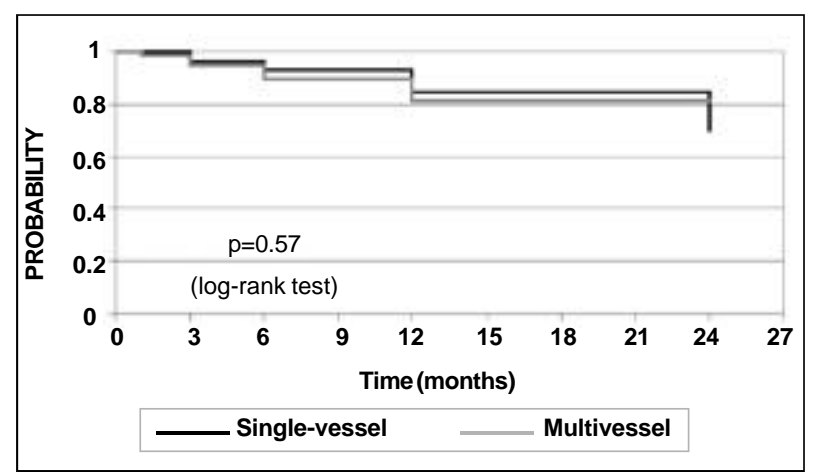

Fig. 1 - Event-free survival

$18.5 \pm 6.4$ months, a greater mortality was observed in the surgical group $(7.5 \%$ vs $3.1 \%)(\mathrm{P}<0.01)$, as was a greater incidence of $\mathrm{Q}$ infarction $(6.3 \%$ vs $2.3 \%)(\mathrm{P}<0.01)$; however, the need for revascularization was more frequent in the group undergoing percutaneous treatment $(16.8 \%$ vs $4.8 \%)(\mathrm{P}<0.01)$.

Our results showed event rates (death, infarction, and need for revascularization) lower than those found in the above-cited studies ${ }^{7,19,20}$, which may be explained by the nonrandomization with selection of more appropriate patients for coronary intervention, a low prevalence of patients with triple-vessel disease, and shorter clinical follow-up.

Considering that coronary atherosclerosis is an evolutionary chronic disease, the percutaneous therapy, being less invasive as compared with the surgical treatment, is an attractive treatment option, mainly for young patients with coronary artery disease.

Hernandez-Antolin et $\mathrm{al}^{21}$, in a case series with $136 \mathrm{pa}$ tients with multivessel coronary artery disease undergoing percutaneous treatment with stents, reported a 3-year event-free survival of $75 \%$.

The study by Kornowski et al ${ }^{8}$ compared 398 patients with multivessel coronary artery disease with 1941 patients with single-vessel coronary artery disease treated with stents, both groups with a mean age of $62 \pm 11$ years, and also found favorable results similar to ours. In the group of patients with multivessel coronary artery disease, the procedure was successful in $96 \%$ of the patients, and the need for new revascularization by the end of 1 year was $21 \%$.

Mathew et al ${ }^{22}$, in a study with 175 patients with multivessel coronary artery disease, reported a successful procedure in $98 \%$ of the patients, and, in the 12-month clinical follow-up, the need for new revascularization was $18.3 \%$ and the event-free survival was $80 \%$.

The rates of need for new revascularization in the above-cited studies ${ }^{8,21,22}$, greater than those observed in our patients, may be explained, as already cited, by the fact that our population sample was mainly formed by patients with double-vessel disease (95.9\%), in addition to the shorter clinical follow-up in our study.

Our findings in patients with multivessel coronary artery disease younger than 50 years undergoing coronary stent implantation in a native artery showed favorable inhospital results and rates of major adverse events in the clinical follow-up similar to that found in patients with singlevessel coronary artery disease. The multivessel group showed no increase in the risk of developing renal failure or stroke after coronary intervention. The high rate of clinical success (95.8\%) is worth noting. On late follow-up, $93 \%$ of the patients with multivessel coronary artery disease were asymptomatic, and the rate of new coronary revascularization was $9.8 \%$. The actuarial analysis at the end of 24 months showed an event-free survival of $81.1 \%$.

The use of stents coated with drugs, sirolimus and Taxol, which, in recent randomized studies showed a significant reduction in the rates of restenosis, even in the group of diabetic patients, may provide greater efficacy in the percutaneous treatment of coronary artery disease ${ }^{23-25}$.

Our study had some limitations, because it was a retrospective study with a relatively small number of patients and a large variety of stent designs. Most patients treated had double-vessel coronary artery disease with favorable angiographic characteristics and good ejection fraction. The results cannot necessarily be reproduced in a population with predominantly triple-vessel coronary artery disease, diffuse coronary artery disease, and significant ventricular dysfunction.

In conclusion, our results suggest that percutaneous treatment with coronary artery stents in young ( $<50$ years) patients with multivessel coronary artery disease may be safely performed with a high rate of success, low rate of inhospital complications, and favorable clinical outcome.

The percutaneous treatment of patients with multivessel coronary artery disease did not increase the rate of in-hospital complications or the need for new revascularization as compared with that of patients with single-vessel coronary artery disease.

Stent implantation was an effective strategy in the treatment of patients with multivessel coronary artery disease, mainly the population with predominantly double-vessel coronary artery disease and with good ventricular function.

\section{Acknowledgments}

We thank Débora Durães for data collection and organization. 


\section{References}

1. Mokdad AH, Serdula MK, Dietz WH, Bowman BA, Marks JS, Koplan JP. The spread of the obesity epidemic in the United States, 1991-1998. JAMA 1999; 282: $1519-22$.

2. Grundy SM, Benjamin IJ, Burke GL, et al. Diabetes and cardiovascular disease: A statement for healthcare professionals from the American Heart Association. Circulation 1999; 100: 1134-46.

3. Friesinger GC, Gavin JA. Diabetes and cardiologists: a call to action. J Am Coll Cardiol 2000; 35: 1130-3.

4. Cowley MJ, Vetrovec GW, DiSciascio G, Lewis SA, Hirsh PD, Wolfgang TC. Coronary angioplasty of multiple vessels: short-term outcome and long- term results. Circulation 1985; 72: 1314-20.

5. Nobuyoshi M, Kimura T, Nosaka H, et al. Restenosis after successful percutaneuos transluminal coronary angioplasty: serial angiographic follow-up of 229 patients. J Am Coll Cardiol 1988; 12: 616-23.

6. Serruys PW, Luijten HE, KJ Beatt, et al. Incidence of restenosis after successful coronary angioplasty: a time-related phenomenon: a quantitative angiographic study in 342 consecutive patients at 1,2,3 and 4 months. Circulation 1988; 77 : 361-71.

7. Serruys PW, Ungen F, Sousa JE, et al. Comparison of coronary artery bypass surgery and stenting for the treatment of multivessel disease (ARTS) Trial. N Engl J Med 2001; 344: 1117-24.

8. Kornowski R, Mehran R, Satler L, et al. Procedural results and late clinical outcomes following multivessel coronary stenting. J Am Coll Cardiol 1999; 33: 420-6.

9. Antman E, Bassand JP, Klein W, et al. Myocardial infarction redefined - a consensus document of the Joint European Society of Cardiology/American College of Cardiology Committee for the redefinition of myocardial infarction. J Am Coll Cardiol 2000; 36: 959-69.

10. Braunwald E. Unstable angina: a classification. Circulation 1989; 80: 410-4.

11. Antman EM, Cohen M, Bernink PJLM, et al. The TIMI risk score for unstable angina/non-ST elevation MI: a method for prognostication and therapeutic decision making. JAMA 2000; 284: 835-42

12. Ryan TJ, Faxon DP, Gunnar RM, et al. Guidelines for percutaneous transluminal coronary angioplasty: a report of the American College of Cardiology/American Heart Association task force on assessment of diagnostic and therapeutic cardiovascular procedures (Subcommittee on percutaneous transluminal coronary angioplasty). J Am Coll Cardiol 1988; 12: 529-45.

13. Ellis SG, Vandormael MG, Cowley MJ, et al. Coronary morphologic and clinical determinants of procedural outcomes with angioplasty for multivessel coronary disease: implications for patients selection. Circulation 1990; 82: 1193-202.

14. The TIMI Study Group. Thrombolysis in myocardial infarction (TIMI) trial: phase I findings. N Engl J Med 1985; 312: 932-6.

15. Lawrie GM, Morris CC Jr, Silvers A, et al. The influence of residual disease in coronary artery disease. Circulation 1982; 66; 717-23.

16. Fischman DL, Leon MB, Baim DS, et al. A randomized comparison of coronarystent-placement and balloon angioplasty in the treatment of coronary artery disease. N Engl J Med 1994; 331: 496-501.

17. Serruys PW, de Jaegere P, Kiemeneij F, et al. A comparison of balloon-expandablestent implantation with balloon angioplasty in patients with coronary artery disease. N Engl J Med 1994; 331: 489-95.

18. Serruys PW, Von Hout B, Bounnier H, et al. Randomized comparison of implantation of heparin-coated stents with balloon angioplasty in selected patients with coronary artery disease (BENESTENT II). Lancet 1998; 352: 673-81.

19. Sigwart U, Stables RH, Booth J, et al. Coronary artery bypass surgery versus percutaneous coronary intervention with stent implantation in patients with multivessel coronary artery disease (the Stent or Surgery trial): a randomized controlled trial. Lancet 2002; 360: 965-70.

20. Rodriguez A, Bernardi V, Navia J, et al. Argentine randomized study: coronary angioplasty with stenting versus coronary bypass surgery in patients with multiple-vessel disease (ERACI II): 30-day and one-year follow-up results. J Am Coll Cardiol 2001; 37: 51-8.

21. Hernandez-Antolin R, Alfonso F, Goicole J, et al. Results (> 6 months) of stenting $>1$ major coronary artery in multivessel coronary artery disease. Am J Cardiol 1999; 84: 147-51.

22. Mathew V, Garratt KN, Holmes, Jr DR. Clinical outcomes after multivessel coronary stent implantation. Am Heart J 1999; 138: 1105-10.

23. Morice MC, Serruys PW, Sousa E, et al. A randomized comparison of a sirolimuseluting stent with a standard stent for coronary revascularization. N Engl J Med 2002; 346: 1773-80.

24. Liistro F, Stankovic G, Di Mario C, et al. First clinical experience with a paclitaxel derivate-eluting polymer stent system implantation for in-stent restenosis: immediate and long-term clinical and angiographic outcome. Circulation 2002; 105: 1883-6.

25. De Scheerder I, Huang Y, Dens J, et al. Treatment of in-stent restenosis using paclitaxel eluting stents: results from The Leuven pilot trial. J Am Coll Cardiol 2002; 39(suppl. A): 59A 